Till I learned Faure's invention I could but think of step-down dynamos, at a maia receiving-station, to take energy direct from the electric main with its 80,000 volts, and supply it by secondary 200 volt dynamos or Ioo volt dynamos, through proper distributing wires, to the houses and factories and shops where it is to be used for electric lighting, and sewing-machines, and lathes, and lifts, or whatever other mechanism wants driving power. No:v the thing is to be done much more economically, I hope, and certainly with much greater simplicity and regularity, by keeping a Faure battery of 40,000 cells always being charged direct from the electric main, and applying a methodical system of removing sets of 50 , and placing them on the town-supply circuits, while other sets of 50 are being regularly introduced into the great battery that is being charged, so as to keep its number always within 50 of the proper number, which would be about 40,000 if the potential at the emitting end of the main is 80,000 volts.

\section{SECTION D}

\section{BIOLOGY}

\section{Departmeint of Anthrofology}

Opening Address by Prof. W. H. Flower, LL.D., F.R.S., Pres. Z.S., V.P. Anthrop. Inst., \&C., ChalrmaN OF THE DEPARTMENT

IT is impossible for us to commence the work of this section of the Association without having vividly brought to our minds the loss which has befallen us since our last meeting-the loss of one who was our most characteristic representative of the complex science of anthropology-one who had for many years conducted with extraordinary energy, amidst multifarious other avocations, a series of researches ii.to the history, customs, and physical characters of the early inbabitants of our island, for which he was so especially fitted by his archæological, historical, and literary, as well as his anatumical knowledge, and who was also the most popular and brilliant expositor, to assemblies such as meet together on these occasions, of the results of those researches. I need scarcely say that I refer to Prof. Rolleston.

Within the last few months the study of our subject in this country has received an im alse from the publication of a book -small in size, it is true, but full of materials for thought and instruction-the "Anthropology" of Mr. E. B. Tylor, the first work published in English with that title, and one very different in its scope and method from the old ethnological treatises.

The immense array of facts brought together in a small conpass, the terseness and elegance of the style, the good taste an feeling with which difficult and often burning questions are treated, should give this book a wide circulation among al classes, aud thorougly familiarise both the word and the subject to English readers.

The origin and early history of man's civilisation, his language, his arts of life, his religion, science, and social customs in the primitive conditions of society, are subjects in which, in consequence of their direct continuity with the arts and sciences, religious, political, and social customs among which we all live, by which we are all influenced, and about which we all have opinions, every person of ordinary education can and should take an interest. In fact, really to understand all these problems in the complex condition in which they are presented to us now, we ought to study them in their more simple forms, and trace them as far as may be to their origins.

But, as the author remarks, this book is only an introduction to anthropology, rather than a summary of all that it teaches and some, even those that many consider the most important, branches of the subject are but lightly touched upon, or wholly passed over.

In one of the estimates of the character and opinions of the very remarkable man and eminent statesman, who e death the country was mourning last spring, it was stated: "Lord Beaconsfield had a deep-rosted conviction of the vast importance of race, as determining the relative dominance both of societies and of individuals" (Spectator, April 23, 1881) ; and with re rard to the question of what he meant by "race," we have a key in the last published work of the same acute observer of mankind "Language and religion do not make a race-there is only one thing which makes a race, and that is blood " "Endymion," vol. ii. p. 205). Now "blood" used in this sense is defined as "kindred.; relation by natural descent from a common ancestor. consanguinity" (Webster's "Dictionary"). The study of the true relationship of the different races of men is then not only interesting from a scientific point of view, but of great importance to statcsmanship in such a country as this, embracing subjects representing almost every known modification of the human species, whose varie $l$ and often conflicting interests have to be regulated and provided for. It is to want of appreciation of its importance that many of the inconsistencies and shortcomings of the government of our dependencies and colonies are due, especially the great inconsistency between a favourite English theory and a too common English practice-the former being that all men are morally and intellectually alike, the latter being that all are equally inferior to himself in all respects : both pro. positions egregiously fallacious. The study of race is at a low ebb indeed when we hear the same contemptuous epithet of "nigger" applied indiscriminately by the Englishman abroad to the blacks of the West Coast of Africa, the Kaffirs of Natal, the Lascars of Bombay. the Hindoos of Calcutta, the aborigines of Australia, and even the Maoris of New Zealand!

But how is he to know better? Where in this country is any instruction to be had? Where are the bosks to which he may turn for trustworthy information? The subject, as I have said, is but slightly touched $\mathrm{u}$ pon in the last published treatise on anthropology in our language. The great work of Pritchard, a compendium of all that was known at the time it was written, is now almost entirely out of date. In not a single university or public institution throu ghout the three kingdoms is there any kind of systematic teaching, either of physical or of any other branch of anthropology, except so far as comparative philology may be considered as bearing upon the subject. The one society of which it is the special business to promote the study of these questions, the Anthropological Institute of Great Britain and Ireland, is, I regret to say, far from flourishing. An anthropological museum, in the proper sense of the word, either public or private, does not exist in this country.

What a contrast is this to what we see in almost every other nation in Europe! At Paris there is, first, the Muséum d'Histoire Naturelle, where man, as a zoological subject-almost entirely neglected in our British Museum-has a magnificent gallery allotted to him, abounding not only in illustrations of osteology, but also in models, casts, drawings, and anatomical preparations showing various points in his physical or natural history, which is expounded to the public in the free lectures of the venerable Prof. Quatrefages and his able coadjutor, Dr. Hamy; there is also the vigorous Society of Anthropology, which is stated in the last annual report to number 720 members, showing an increase of forty-four during the year 1880, and which is forming a museum on a most extensive scale; and, finally, the School of Anthropology, founded by the illustrious Broca, whose untimely death last year, instead of paralysing, seems to have stimulated, the energies of colleagues and pupils into increased activity. In this school, supported partly by private subscriptions, partly by the public liberality of the Municipality of Paris, and of the Department of the Seine, are laboratories in which all the processes of anthropological manipulation are practised by students and taught to travellers. Here all the bodies of persons of outlandish nationalities dyin in any of the hospitals of Paris are dissected by competent and zealous observers, who carefully record every peculiarity of structure disc svered, and are thus laying the foundation for an exhaustive and trustworthy collection of materials for the com parative anatomy of the races of man. Here, furthermore, are lectureships on all the different branches. Biological and anatomical anthropology, ethnology, prehistoric, linguistic, social, and medical anthropology are all treated of separately by eminent professors who have made these departments their special study. The influence of so much activity is spreading beyond the capital. The foundation of an anthropological society at Lyons has been announced within the present year.

In Germany, although there is not at present any institu'ion organised like the school at Paris, the flourishing state of the Berlin Ethnological Society, which also reports a large increase in the number of its members, the various other societies and journals, and the important contributions which are continually being made fron the numerous intellectual centres of that land of learning, all attest the interest which the study of man excites there. In Italy, in the Scandinavian kinzdoms, in Russia, and even in Spain, there are signs of similar activity. A glance at the recent periodical literature of America, especially the publicat:ons of the Smithsonian Institution, will show how strongly 
the scientific work of that country is setting in the same direction.

It is true that a very great proportion of the energies of the societies, institutions, and individuals who cultivate this vast subject are, in all these lands, as it is indeed to so great an extent in our own, devoted to that branch which borders upon the old and favourite studies of archæology and geology. The fascinating power of the pursuit of the earliest traces of man's existence upon the earth, with the possibilities of obtaining some glimpses of his mode of origin, is attested in the devotion seen everywhere in museums, in separate publications, and in journals, to pre-historic anthropology.

But, though the study of man's origin and earliest appearances upon the earth, and that of the structural modifications to which in course of time he has arrived, or the study of races, are intimately related, and will ultimately throw light upon one another, I venture to think that the latter is the more pressing of the two, as it is certainly the more practically important; and hence the necessity for greater attention to physical anthropology. In seeking for a criterion upon which to base our study of races, in looking for essential proofs of consanguinity of descent from common ancestors in different groups of men, I bave no hesita* tion in saying that we must first look to their physical or anatomical characters, next to their moral and intellectual cha. racters-for our purpose more difficult of apprehension and comparison-and, lastly, as affording hints, of ten valuable in aid of our researches, but rarely to be depended upon, unless corroborated from other sources, to language, religion, and social customs.

The study of the physical or anatomical character of the races of man is unfortunately a stubject beset with innumerable difficulties. It can only be approached with full advantage by one already acquainted with the ordinary facts of human anatomy, and with a certain amount of zoological training. The methods used by the zoologist in discriminatinz species and varieties of animals, and the practice acquired in detecting minute resemblances and differences that an ordinary observer might overlook, are just what are required in the physical anthropologist.

As the great problem which is at the root of all zoology is to discover a natural classification of animals, so the aim of zoological anthropology is to discover a natural classification of man. A natural classification is an expression of our knowledge of real relationship, of consanguinity-of "blood," as the author of "Endymion" expresses it. When we can satisfactorily prove that any two of the known groups of mankind are descended from the same common stock, a point is gained. The more such points we have acquired, the more nearly shall we be able to picture to ourselves, not only the present, but the past distribution of the races of man upon the earth, and the mode and order in which they have been derived from one another.

The difficulties in the way of applying zoological principles to the classification of man are vastly greater than in the case of most animals; the problem being, as we shall see, one of much greater complexity. When groups of animals become so far differentiated from each other as to represent separate species, they remain isolated; they may break up into further sub. divisions-in fact, it is only by further subdivision that new species can be formed; but it is of the very essence of species, as now universally understood by naturalists, that they cannot recombine, and so give rise to new forms. With the varieties of man it is otherwise. They have never so far separated as to answer to the physiological definition of species. All races are fertile one with another, though perhaps in different degrees. Hence new varieties have constantly been formed, not only by the segmentation, as it were, of a portion of one of the old stocks, but also by various combinations of those already established.

Neither of the old conceptions of the history of man, which pervaded the thought, and form the foundation of the works of all ethnological writers up to the last few years, rest on any solid basis, nor account for the phenomena of the present condition and distribution of the species.

The one view-that of the monogenist-was that all races, as we see them now, are the descendants of a single pair, who, in a comparatively short period of time, spread over the world from one common centre of origin, and became modified by degrees in consequence of changes of climate and other external conditions. The other-that of the polygenist-is that a certain number of varieties or species (no agreement has been arrived at as to the number, which is estimated by different authorities at from three to 1 wenty or more) have been independently created in different parts of the world, and have perpetuated the distinctive characters as well as the geographical position with which they were originally endower.

The view which appears best to accord with what is now known of the characters and distribution of the races of man, and with the general phenomena of nature, may be described as a modification of the former of these hypotheses.

Without entering into the difficult question of the method of man's fir:t appearance upon the world, we must assume for it a vast antiquity - at all events as measured by any bistorical standard. Of this there is now ample proof. During the long time he existed in the savage state-a time compared to which the dawn of our historical period vas as yesterday-he was influenced by the oreration of those natural laws which have produced the variations seen in other regions of organic nature. The first men may very probably have been all alike; but, when spread over the face of the earth, and become subject to all kinds of diverse external conditions-climate, food, competition with members of his own species or with wild animals-racial differences began slowly to be developed through the potency of various kinds of selection acting upon the slight variations which appeared in individuals in obedience to the tendency implanted in all living things.

Geographical position must have been one of the main elements in determining the formation and the permanence of races. Groups of men isolated from their fellows for long periods, such as those living on small islands, to which their ancestors may have been accidentally drifted, would naturally, in course of time, develop a new type of features, of skull, of complexion or hair. A slight set in one direction, in any of these characters, would constantly tend to intensify itself, and so new races would be formed. In the same way different intellectual or moral qualities would be gradually developed and transmitted in different groups of men. The longer a race thus formed remained isolated, the more strongly impressed and the more permanent would its characteristics become, and less liable to be changed or lost, when the surroundirg circumstances were altered, or under a moderate amount of intermixture from other races- the more "true," in fact, would it be. On the other hand, on large continental tracts, where no "mountains interposed make enemies of nations," or other natural barriers form obstacles to free intercourse betwcen tribe and tribe, there would always be a tendency towards uniformity, from the amalgamation of races brought into close relation by war or by commerce. Smaller or feebler races have been destroyed or absorbed by others impelled by : uperabundant population or other causes to spread beyond their original limits; or sometimes the conquering race has itself disappeared by absorption into the conquered.

Thus, for untold ages, the history of man has presented a shifting kaleidoscopic scene ; new races gradually becoming differentiated out of the old elements, and, after dwelling a while upon the earth, either becoming suddenly annihilated or gradu. ally merged into new combinations; a constant destruction and reconstruction; a constant tendency to separation and differentiation, and a tendency to combine again into a common uniformity - the two tendencies acting against and modifying each other. The history of these processes in former times, except in so far as they may be inferred from the present state of things, is a difficult study, owing to the scarcity of evidence. If we had any approach to a complete palæontological record, the history of man could be reconstructed : but nothing of the kind is forthcoming. Evidences of the anatomical characters of man as he lived on the earth during the time when the great racial characteristics were being developed, during the long antehistoric period in which the negro, the Mongolian, and the Cattcasian were being gradually fashioned into their respective types, is entirely wanting, or, if any exists, it is at present safely buried in the earth, perhaps to be revealed at some unexpected time and in some unforcseen manner.

It will be observed, and perhaps observed with perplexity by some, that no definition has as yet been given of the oft-recurring word "race." The sketch just drawn of the rast history of man must be sufficient to show that any theory implying that the different individuals composing the human species can be parcelled out into certain definite groups, each with its well-marked and permanent limits separating it from all others, has no scientific foundation; but that in reality these individuals are aggregated into a number of groups of very different value in a zoological sense, with characters more or less strongly marked 
and permanent, and often passing insensibly into one another. The great groups are $s_{s}$ lit up into minor subdivisions, and filling up the gaps between them all are intermediate or intercalary forms, derived either from the survival of individuals retaining the generalised or ancestral characters of a race from which two branches have separated and taken op posite lines of modification, or from the reunion of members of such branches in recent times. If we could follow those authors who can classify mankind into such divisions as trunks, branches, races, and sub-races, each having its definite and equivalent meaning, our work would appear to be greatly simplified, although perhaps we should not be so near the truth we are seeking. But being not yet in a position to define what am unt of modification is necessary to constitute distinction of race, I am compelled to use the word vaguely for any considerable group of men who resemble each other in certain common characters transiuitted from generation to generation.

In approaching the question of the classification of the races of man from a physical point of view, we must bestow great care upon the characters upon which we rely in distinguishing one group from another. It is well known in zoology that the modifications of a single organ or system may be of great value, or may be quite useless a"cording as such modifications are correlated with others in different organs or systems, or are mere isolated examples of variation in the economy of the arimal without structural changes elsewhere. The older ornithologists associated in one order all the birds with webbed feet, and the order thus constituted, Natatores or Palmipedes, which received the great sanction of Cuvier, still stands in many zoological compilations. Recent investigations into the anatomy of birds have shown that the species thus associated together show no other sign of natural affizity, and no evidence of being derived from the same stock. In fact, there is tolerably good pro of that the webbing of the feet is a merely adaptive character, developed or lost, present or absent, irrespective of other structural modificatioas. In the same way, when anthropology was less advanced than it is $n>w$, it was thought that the distinction between loag and sho:t-headed, dolich ocephalic and brachycephalic, people, pointed out by Retzius, indicated a prinary division of the human species; but it was afterwards discovered that, although the character was useful otherwise, it was one of only secondary importance, as the long-headed as well as the shortheaded group both incladed races otherwise of the stro.ngest dissimilarity.

In all classifications the point to be first ascertained is the fundamental plan of construction; but in cases where the funda. mental plan has undergone but little modification, we are obliged to make use of what appear trivial characters, and compeasate for their triviality by their number. The $m$ re numerous the combinations of specialised characters, by which any species or race differs from its congeners, the more confidence we have in their importance. The separation of what is essential from what is incidental or merely superficial in such characters lies at the root of all the proble as of this nature that zoslogists are called upon to solve; and in propsrtion as the difficultie: involved in thi; delicate and often perplexing discrimination are successfully met and overcome will the value of the conclusions be increased. These difficulties, so familiar in zoology, are still greater in the case of anthropology. The differences we have to deal with are often very slight ; their significance is at present very little understood. We go on expending time and trouble in heaping up elaborate tables of measurements, and minutely recording every point that is capable of description, with little regard to any conclusions that may be drawn from them. It is certainly time now to endeavour, if possible, to discriminate characters which indicate deep-lying affinity from those that are more transient, variable, or ad iptive, and to adjust, as far as may be, the proper importance to be attached to each.

It is, however, quite to be expected that, in the infancy of all sciences, a vast amount of $1 \mathrm{bbour}$ must be expended in learning the methods of investigation. In none has this been more conspicuous than in the su'sject moder consideration. Many have come to despair, for instance, of any good commensurate with the time it occuivies, coming of the minute and laborious work involved in craniometry. This is because nearly all our present methods are tentative. We have not yet learnt, or are only be ginning to learn, what lines of investigation are profitable and what are barren. The results, even as far as we have gone, are, however, quite sufficient, in my opinion, to justify perseverance. I am, however, not so sure whether it be yet time to answer the demand, so eager and so natural, which is being made in many quarters, for the formulation of a definite plan of examination, measurement, and description to which all future investigation should rigidly adliere. All steps to promote agreement upon fundamental points are to be cordially wel. c med, and meetings or congresses convened for such a purpose will be of use by giving opportunities fur the impartial discussion of the relative value of different methods; but the agreement will finally be brought about by the general adoption of those measurements and methods which experience proves to be the most useful, while others will gradually fall into disuse by a kind of process of natural selection.

The changes and improvements which are being made yearly, almost monthly, in instruments and in methods, show what we should lose if we were to stop at any given period, and decree in soleinn $\mathrm{c}$-nclave that this shall be our final system, this instrument and this method shall be the only one used throughout the world, that no one shall depart from it. We scarcely need to ask how long such an agreement would be binding. The subject is not sufficiently advanced to be reduced to a state of stagnation sush as this would bring it to.

To take an example from what is perhaps the most important of the anatomical characters by which man is distinguished from the lower animals, the superior from the inferior races of man; the smaller or greater projection forwards of the lower part of the face in relation to the skull proper, or that which contains the brain. From the time when Camper drew his facial angle, to the present day, the readiest and truest method of estimating this projection has occupied the attention of anatomists and anthropologists, and we are still far from any general agreement. Every country, every school, has its own system, so different that comparison with one another is well nigh impossible. This is undoubtedly an evil ; but the question is whether we should all agree to adopt one of the confessedly defective systems now in vogue, or whe'her we should not rather continue to hope for, and endeav sur to find, one which may not be subject to the well-known objections urged against all.

We want, especially in this country, more workers, trained and experienced men who will take $u$, the subject seriously, and devote themselves to it continuunsly. Of such we may say, without offence to those few who have done occasional excellent work in physical anthropol igy, but whose chief scientific activity lies in other field=, we have not one. In the last number of the French Revue d'Anthropologie, a reference caught my eye to a craniometrical method in u e by the "English school" of anthropologists. It was a reference only to a method which I had ventured to suggest, but which, as far as I know, has not been adopted by any one elee. A school is just what we have not, and what we want-a body of men not only willing to learn, but able to discuss, to criticise, to give their approval to, or reduce to its proper level, the results put forth by our few original investigators and writers. The rapidity with which any one of the most slender pretensions who ventures into the field (I speak from painful experience) is raised to be an oracle among his fellows is one of the most alarming proofs of the present barrenness of the land.

Another no t urgent need is the collection and preservation of the evidences of the physical structure of the various modifications of man upon the earth. Especially urgent is this now, as we live in an age in which, in a far greater degree than any previous one, the destructi $\mathrm{n}$ of races, both by annibilation and absorption, is going on. The world has never witnessed such changes in its ethn slogy as those now taking place, owing to the rapid extension of maritime di-covery and maritime commerce, which is especially affecting the island population among which, more than elsewhere, the solution of the most important anthropological problems may be looked fo: If we have at present neither the knowled se nor the leisure to examine and describe, we can at lea-t pre erve from destruction the materials for our successors to work $u_{1}$ l. 1 . Photozraphs, molels, anatomical specimens, ske'etons or parts of skeletons, with their histories carefully registered, of any of the so-called aboriginal race:, now rapidly undergoing extermination or degeneration, will be hereafter of inestimable value. Drawings, descriptions, and measurements are also useful, though in a far less degree, as allowance must always be made for imperfections in the me! hods as well as the capacity of the a tist or observer. Such co'lections must be made upon a far larger scale than has hitherto been attempted, as, owing to the difficulties already pointed out in the classifica. tion of man, it is o:ily by large numbers that the errors arising 
from individual peculiarities or accidental admixture can be obviated, and the prevailing characteristics of a race or group truly ascertained. It is only in an institution commanding the resources of the nation that such a collection can be formed, and it may therefore be confidently hoped that the trustees of the British Museum will appropriate some portion of the magnificent new brilding, which has been provided for the accommodation of their natural history collections, to this hitherto neglected branch of the subject.

I have mentioned two of the needs of anthropology in this country-more workers and better collections: there is still a third-that of a society or institution in which anthropologists can meet and discuss their respective views, with a journal in which the results of their investigations can be laid befo:e the public, and a library in which they can find the books and periodicals necessary for their study. All this ought to be provided by the Anthropological Institute of Great Britain and Ireland, which originated in the amalgamation of the old Ethnological and Anthropological Societies. But, as I intimated some time agro, the Institute does not at the present time flourish $a_{\text {; }}$ it should ; its meetings are not so well attende 1 as they might be; the journal is restricted in its powers of illustration and printing by want of funds; the library is quite insufficient for the needs of the student.

This certainly does not arise from any want of good management in the Society itself. Its afairs have been presided over and administered by some of the most eminent and.able men the country has produced. Huxley, lubbock, Busk, Evans, Tylor, and Pitt-Rivers have in succession given their energies to its service, and yet the number of its members is falling away, its usefulness is crippled, and its very existence seems precarious. Some decline to join the Institute, others leave it ujon the plea that, being unable from distance or other cause; to attend the meetings, they cannot obtain the full return for their subscriptions; others on the ground that the journal does not contain the exact information which they require.

There surely is to be found a sufficient number of persons who are influenced by different considerations, who feel that authropological science is worth cultivating, and that those who are laboriously and patiently tracing out the complex problems of man's diversity and man's early history are doin $z$ a good work, and ought to be encouraged by havin the means affurde $i$ them of carrying on their investigations and of placing the results of their researches before the world-who feel, moreover, that there ought to be so ne central body, representing the subject, which may, on occasion, influence opinio 1 or speak authoritatively on matters often of great practical importance to the nation.

There must be many in this great and wealthy country who feel that they are helping a good cause in joining such a society, even if they are not individually receiving what they consider a full equivalent for the r small sub cription-many who feel satisfaction in helping the cause of knowledge, in helping to remove the opprobrium that the British Anthropological Society alone of tho e of the world is lacking in vitality, aur in helping to prevent this country from falling behind all the nations in the cultivation of a science in which, for the strongest reasons, it might be expected to hold the foremost place. It is a far more gratefui lask to maintain, extend, and if need be improve, an existing organisation, than to con tract a new one. I feel, therefore, no hesitation in urging upon all who take interest in the promotion of the study of anthropology to rally round the Institute, and to support the eudeavours of the present excellent president to increase its usefulness.

\section{Department of Anatomy and Physiology'}

Opening AdDress by J. BuRdon-SAndLRson, M.D., LLD., F.R.S., Professor of Physiology in University ColLEGE, LONDON, VICE-PRESIDENT OF THE SECTION

On the Discoveries of the Past Half-Century relating to Animal
Motion

Tine two great branches of Biology with which we concern ourselves in this section, Animal Morphology and Physiology, are mo intimately related to each other. This arises from their having one sulject of study-the living animal organism. The difference betwcen them lics in this, that whereas the studies of the anatomist lead him to fix his attention on the organism itself, to us physiologists it, and the organs of which it is made up, serve only as vestigia, by means of which we investigate the vital processes of which they are alike the causes and consequences.

To illustrate this I will first ask you to imagine for a moment that you have before you one of those melancholy remainders of what was once an animal-to wit, a rabbit - which one sees exposed in the shops of poulterers. We have no hesitation in recognising that remainder as being in a certain sense a rabbit; but it is a very miscrable vestige of what was a few days ago enjoying life in some wood or warren, or more likely on the sand-hills near Ostend. We may call it a rabbit if we like, but it is only a remainder-not the thing itself.

The anatomical preparation which I have in imagination placed before you, although it has lost its inside and its outside, its integument and its viscera, still retains the parts for which the rest existed. The final cause of an animal, whether human or other, is muscular action, because it is by means of it.s muscles that it maintains its external relations. It is by our muscles exclusively that we act on each other. The articulate sound; by which I am addressing you are but the results of complicated combinations of muecular contraction-and so are the scarccly appreciable changes in your countenances by which I am able to judge how much, or how little, what I am saying interests you.

Consequently the main problems of physiology relate to muscular action, or, as I have called it, animal motion. They may be divided into two-namely (I) in what does muscular action consist-that is, what is the process of which it is the effect or outeome? and (2) how are the motions of our bodies co-ordinated or regulated? It is unnecessary to occupy time in showing that, excluding those higher intellectual processes which, as they leave no traceable marks behind them, are beyond the reach of our methods of investigation, these two questions comprise all others concerning animal motion. I will therefore proceed at once to the first of them-that of the process of muscular contraction.

The years which immediately followed the origin of the British Association exceeded any carlier period of cqual length in the number and importance of the new fact; in morphology and in physiology which were brought to light ; for it was during that period that Johannes Miiller, Schwann, Henle, and, in this country, Sharpey, Bowman, and Marshall Hall, accomplished their productive labours. But it was introductory to a much greater epoch. It would give you a true idea of the nature of the great advance which took place about the middle of this century if I were to define it as the epoch of the death of "vitalism." Before that time, even the greatest biologist-e.g. J. Miiller-recognised that the knowledge they possessed both of vital and physical phenomena was insufficient to refer both to a common measure. The method, therefore, was to study the processes of life in relation to cach other only. Since that time it has become fundamental in our science not to regard any vital process as understood at all, unless it can be brought into relation with physical standards, and the methods of physiology have been based exclusively on this principle. Let us inquire for a moment what causes have conduced to the change.

The most efficient cause was the progress which had been made in physics and chemistry, and particularly those investigations which led to the establishment of the doctrine of the Conservation of Energy. In the application of this great principle to physiology, the men to whom we are indebted are, first and foremost, I. R. Mayer, of whom I shall say more immediately; and secondly, to the great physiologists still living and working among us, who were the pupils of $\mathrm{J}$. Miiller-viz. Helmholtz, Ludwig, Du Bois-Reymond, and Bricke.

As regard; the subject which is first to occupy our attention, that of the process of muculax contraction, I. R. Mayer occupies so leading a position that a large proportion of the researches which have been dome since the now era, which he had so important a share in establishing, may be rightly considered as the working out of principles enunciated in his treatice ${ }^{x}$ on the relation between organic motion and exchange of material. The most important of these were, as expressed in bis own words: (I) "That the chemical force contained in the ingested food and in the inhaled oxygen is the source of the motion and heat which are the two products of animal life; and (2) that these products vary in amount with the chemical process which produces them." Whatever may be the claims of Mayer to be regarded as a great discover in physics, there can be no doubt

I J. R. Mayer, "Die organische Bewegung in ihrem Zusammenhange mit dem Stoffwechsel: ein Beitrag zur Naturkunde," Heilbronn, 1845. 